\title{
Prevalence and Risk Factors of Hypertension Among Adults in Nagarjun Municipality of Kathamandu District
}

\author{
Sailendra Thapa ${ }^{*}$, Ridesh Pokharel*, Durga Khadka Mishra, Rajan Bhusal \\ Department of Public Health, Manmohan Memorial Institute of Health Sciences, Kathmandu, Nepal \\ Email address: \\ thapasailen@gmail.com (S. Thapa), ridesh46@gmail.com (R. Pokharel), rideshpokharel99@gmail.com (R. Pokharel) \\ ${ }^{*}$ Corresponding author
}

\section{To cite this article:}

Sailendra Thapa, Ridesh Pokharel, Durga Khadka Mishra, Rajan Bhusal. Prevalence and Risk Factors of Hypertension Among Adults in Nagarjun Municipality of Kathamandu District. Journal of Family Medicine and Health Care. Vol. 5, No. 2, 2019 , pp. 15-21. doi: $10.11648 /$ j.jfmhc.20190502.11

Received: June 19, 2019; Accepted: July 10, 2019; Published: July 23, 2019

\begin{abstract}
Hypertension plays a persistent role in the causation of coronary heart disease, stroke, and vascular problems. Many factors like dietary, behavioral, psychological, environmental, genetic, etc have a direct or indirect influence on hypertension. The available evidences shows a higher prevalence of hypertension in Nepal. The objective of this study was to assess the prevalence and risk factors associated with hypertension among adults of Nagarjun Municipality. A descriptive cross-sectional study was conducted among adults of age 18 and above in Nagarjun municipality. A structured questionnaire was used to assess the risk factors and observation was done to determine blood pressure and anthropometric measurement. The data were entered and analyzed by (SPSS) software version 20. Chi-square test was used to identify the association. The overall prevalence of hypertension was $22.8 \%$ and prehypertension was $14.5 \%$. More males were found to have hypertension (28.09\%) compared to females (16.67\%). Age, sex, religion, socio-economic status, ciggrate smoking, alcohol consumption, BMI, diabetes, family history of hypertension and cardio vascular disease was found to be significantly associated with hypertension. The preventive and intervention measures should be adopted to reduce the behavioral and biological risk factors which are directly related with the causation of hypertension.
\end{abstract}

Keywords: Hypertension, Risk Factors, Adults, Nagarjun Municipality

\section{Introduction}

The Seventh Report of the Joint National Committee on Prevention Detection Evaluation, and Treatment of high blood pressure (JNC VII) defined hypertension as higher than $140 \mathrm{~mm}$ of $\mathrm{Hg}$ of a systolic blood pressure and/or higher than $90 \mathrm{~mm}$ of $\mathrm{Hg}$ of a diastolic blood pressure depending upon the mean of two or more measurement of correct blood pressure taken during contacts with a health professional [1]. The 7.5 million deaths is regarded to be a cause of hypertension and account for $12.8 \%$ of all deaths and is a major risk factor for cardiovascular disease [2].

Hypertension is divided into primary (essential) and secondary. When the causes are generally unknown it is classified as essential hypertension and accounts for 90 percent cases of all hypertension. When abnormality or other disease process is involved in causation categorized as "secondary" hypertension. "Rules of halves" describes that there are high number of hypertensive people in the community while only few are diagnosed; among the diagnosed people; only few undergoes treatment and very few people are adequately treated. The country in a posttransition stage of economy and epidemiology the higher blood pressure have been noted among the group of lower socio-economic class [3].

Hypertension accounts risk factors for the many forms of cardiovascular disease but its own factors are cause for this condition [4].Whereas, the society in transition and pretransition phase the prevalence of hypertension has been found high among people of the higher socio-economic class [5]. The situation of Nepal is quite similar as the country is facing changes in epidemiology, economic and also the political phase is in transition phase. About $35 \%$ of the adult population in South-East Asia Region has hypertension, which is a cause of about 1.5 million deaths in a year; out of 
the total deaths hypertension is associated with $9.4 \%$ deaths [6]. In Nepalese community hypertension prevalence was found to be triple in 25 years in rural Kathmandu showed by a repeat cross-sectional study [7]. If hypertension is not treated and controlled it can make a huge impact on the medical, economy and human [8].

\section{Methods}

\subsection{Study Design, Setting and Participants}

A descriptive cross sectional study was conducted in Nagarjun municipality of Kathmandu distict from $18^{\text {th }}$ April to $14^{\text {th }}$ May, 2018. The quantitative method was used in the study. The study subjects were adults of age equal to 18 and older. The respondent only include the people who were included in the voter list of municipality office.

\subsection{Sample Size}

From literature review, Prevalence and Associated factors of Hypertension among Adults in Rural Nepal: A community based study Chataut J, Khanal K, Manandhar K. The sample size of 276 was fixed using the formula:

$$
\begin{gathered}
\mathrm{n}=\left(Z^{2} \mathrm{pq}\right) / \mathrm{d}^{2} \\
=1.96 * 1.96 * 0.205 * 0.795 / 0.05 * 0.05
\end{gathered}
$$

where, $z=1.96$ (at $5 \%$ level of significance); $d=0.05, p=$ expected proportion in population which is $20.5 \%$ i.e. $0.205 .10 \%, q=1-p=1-0.205=0.795$; out of sample size $10 \%$ was taken as non-response rate, the final sample size was:

$$
\begin{aligned}
& =251 \\
& =251+10 \% \text { of } 251 \\
& =276
\end{aligned}
$$

\subsection{Sampling Techniques}

The study population of age equal to 18 or older were selected from the registered voter list obtained from municipality office and first house was selected randomly by bottle spinning method from ahead of each ward office and eligible respondent were randomly selected if there were more than one eligibile respondent in a house. Simple random sampling technique was used for The municipality consists of ten wards out of which three wards were selected randomly. There were a total 30,380 adults age 18 and older in the municipality.

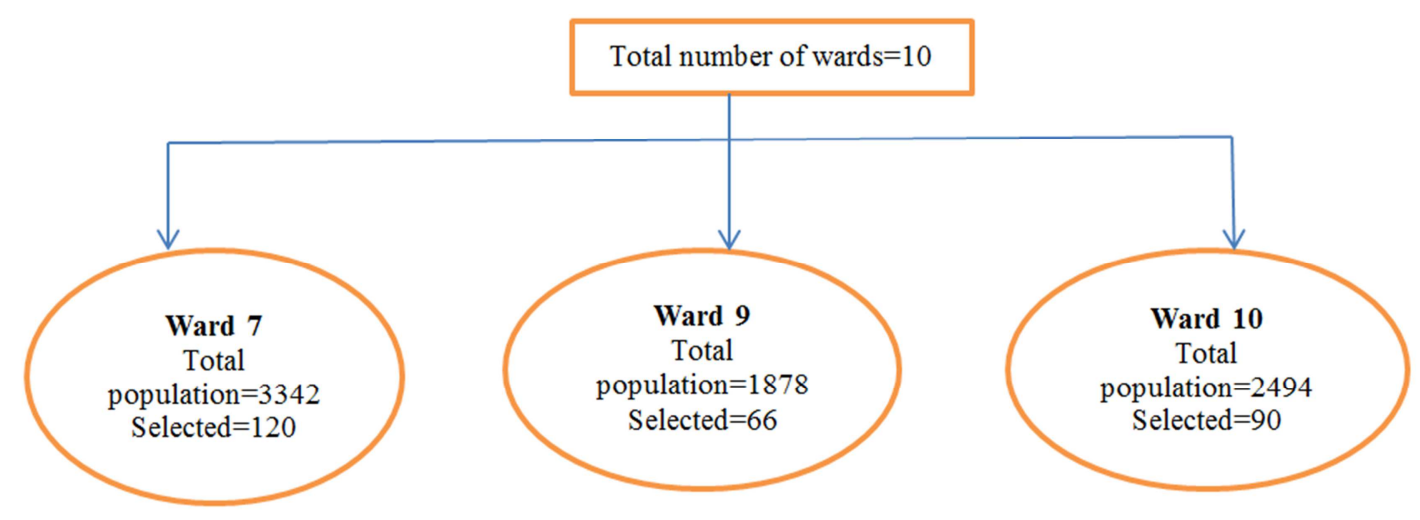

Figure 1. Sample size from each ward.

Figure 1 shows the calculation of sample size from ward 7, 9 and 10.

\subsection{Criteria for Sample Selection}

Inclusion criteria: Individuals age 18 and above

Exclusion criteria: Pregnant women, individuals unable to response due to serious physical or mental illness.

\subsection{Data Collection Tools}

1. Bathroom scale weighing machine

2. Measuring tape (fiber glass measuring tape)

3. Sphygmomanometer, Stethoscope

For blood pressure measurement: Blood pressure was measured by the auscultatory method with mercury sphygmomanometer with standard cuff $(12 * 34 \mathrm{~cm})$. The blood pressure measurement was taken in the quietly seated position, with arms at the heart level. The intake caffeine, exercise and smoking were restricted for at least 30 minutes before measurement. Systolic Blood Pressure is the point at which first of the two or more korotkoff sound is heard and disappearance of korotkoff sound is used to define Diastolic Blood Pressure The two blood pressure measurement was taken 5 minutes apart. Average of the two readings was taken. BP more than 140/90 was considered as hypertension according to JNC VII criteria.

Measurement of height: Height measurement was done using measuring tape (fiber glass measuring tape). The respondents were told to remove all shoes and socks and stand on a flat floor with no carpeting next to a wall with his/her feet together and heels touching the wall looking straight ahead and keeping shoulders at same level. A flat ruler was placed onto his/her head, and the person was asked to move out. The floor to the flat ruler distance was measured with a tape and height was recorded.

Weight measurement: Weight was taken using bathroom scale weighing machine. The scale was placed on a flat surface and the meter was adjusted to zero. The respondents were asked to step on it in bare feet with minimum clothes. 


\subsection{Data Collection Techniques}

The structured questionnaire was used to collect the data through interview technique. The information about demographic, biological and behavioral factors was obtained through questionnaire. Apart from interview, examination of blood pressure and anthropometric measurements was carried out. The four principle of ethics namely autonomy, nonmaleficence, beneficence and justice for the participants was carried during the study time.

\subsection{Pre-testing of Data Collection}

The study instrument was pre-tested to identify the consistency of the tools at Kritipur Municipality. The questionnaire was revised and techniques to handle tools were correctly identified after pre-testing. Consultation with the experts was done for necessary changes for the further process in data collection.

\subsection{Ethical Consideration}

The formal approval was taken from Institutional Review Committee (IRC) of Manmohan Memorial Institute of Health Sciences. The participants was informed and counseled about aims, methods and anticipated benefits and of the study program. Written and verbal informed consent was taken with each and every respondent. Neither pressure nor inducement was done to encourage any person to participate in the study. During the study period all the ethical consideration as well as confidentiality was maintained to respect for human dignity and principle of justice.

\subsection{Operational Definitions}

The Seventh Report of the Joint National Committee on Prevention Detection Evaluation, and Treatment of high blood pressure (JNC VII) defined hypertension as higher than $140 \mathrm{~mm}$ of $\mathrm{Hg}$ of a systolic blood pressure and higher than $90 \mathrm{~mm}$ of $\mathrm{Hg}$ of a diastolic blood pressure depending upon the mean of two or more measurement of correct blood pressure taken during contacts with a health professional. The systolic blood pressure (SBP) greater than or equal to $140 \mathrm{mmHg}$ and/or a diastolic blood pressure (DBP) greater than or equal to $90 \mathrm{mmHg}$ was classified hypertension, prehypertension SBP 120-130/DBP 80-89, Stage 1 hypertension SBP 140-159/DBP 90-99, Stage 2 hypertension $>160 /$ DBP $>100$ as recommended by JNC VII [1]. The respondents who were using anti-hypertensive medicine were classified as hypertensive. In Nepal, age 18 and above are regarded as adult; per day income was calculated from the total earnings from family members in the year and was compared with one dollar. The earnings less than one dollar was classified as below poverty and more than one dollar was classified as above poverty.
The current smokers were any respondents smoking of tobacco products in last 30 days with minimum of 100 cigarettes smoking in their life and the respondent not smoking during study was classified as past smoker [9]. The consumption of alcohol with in last 30 days considered as current alcohol drinkers [9]. Whereas, the consumption of at least $400 \mathrm{gm}$ of fruit and vegetables is considered sufficient [9]; the weight-for-height index used in classification for underweight, overweight and obesity in adults. The weight in kilograms divided by the square of the height in meters $\left(\mathrm{kg} / \mathrm{m}^{2}\right)$ is term as BMI. BMI less than $18.5\left(\mathrm{~kg} / \mathrm{m}^{2}\right)$ classified as underweight, 18.5-24.9 $\left(\mathrm{kg} / \mathrm{m}^{2}\right)$ as normal weight, $25-29.9\left(\mathrm{~kg} / \mathrm{m}^{2}\right)$ as overweight, $30-34.9\left(\mathrm{~kg} / \mathrm{m}^{2}\right)$ as obesity class $1,35-39.9\left(\mathrm{~kg} / \mathrm{m}^{2}\right)$ as obesity class 2 and $>40$ $\left(\mathrm{kg} / \mathrm{m}^{2}\right)$ as extreme obesity class 3 [10]; the respondents with present status of diabetes or had medication history for diabetes [11].

According to WHO (Principal of Nutrition Assessment), the level of physical activity is categorized as high, moderate, or low according to the following criteria:

Vigorous/High: A person meeting any of the following criteria; Vigorous-intensity activity of at least 1.500 METminutes/week achieved on at least 3 days; or any combination of walking, moderate-or-vigorous-intensity activity achieving of at least 3,000 MET-minutes per week on 7 days.

Moderate: A person not meeting the criteria for 'high' level of activity, but meeting any of the following criteria; At least 20 minutes per day of vigorous intensity-activity consisting of 3 or more days at least 30 minutes per day of moderate intensity activity or walking in 5 or more days; at least 600 MET-minutes per day of moderate or vigorousintensity activity in 5 or more days of any combination of walking.

\subsection{Data Management and Analysis}

The data was entered, coded, analyzed, and interpreted according to the objective of the study using SPSSv20.0 software, MS Excel.

\section{Results}

Characteristics of respondents:

Socio-demographic, behavioral and biological characteristics of the respondent.

Table 1 shows the socio-demographic characteristics of the respondent. The age group of most of the respondents was 19-18 $(22.5 \%)$ and the mean age of the respondents was 43.22 (S.D $=16.508)$. In response to behavioral factors, $42.4 \%$ of respondents were current alcohol consumer. In the assessment of biological factors $93.1 \%$ of the respondents were non-obese, $29 \%$ had family history of hypertension and CVD family history was found among $29.7 \%$ of the respondents. 
Table 1. Socio-demographic, behavioral and biological characteristic of the respondents.

\begin{tabular}{|c|c|c|c|}
\hline Variables & Category & Number (n) & Percentage $(\%)$ \\
\hline \multicolumn{4}{|l|}{ Socio-demographic factors of the respondents } \\
\hline \multicolumn{4}{|l|}{ Age } \\
\hline Mean $=43.22$ & $18-40$ & 130 & 47.1 \\
\hline S.D $=16.508$ & $41-88$ & 146 & 52.9 \\
\hline \multirow{2}{*}{ Sex } & Male & 150 & 54.3 \\
\hline & Female & 126 & 45.7 \\
\hline Ethnicity & Bhramin/Chhetri & 135 & 48.9 \\
\hline \multirow{2}{*}{ Religion } & Hindu & 226 & 81.9 \\
\hline & Non-hindu & 50 & 18.1 \\
\hline \multirow{2}{*}{ Educational status } & Illiterate & 30 & 10.9 \\
\hline & Literate & 246 & 89.1 \\
\hline \multirow{2}{*}{ Marital Status } & Unmarried & 44 & 15.9 \\
\hline & Ever-married & 232 & 84.1 \\
\hline Occupational status & Employed & 173 & 62.7 \\
\hline Socio-economic status & Above poverty & 243 & 88.0 \\
\hline \multicolumn{4}{|l|}{ Behavioral factors of the respondents } \\
\hline \multirow{2}{*}{ Habit of cigarette smoking currently } & Yes & 80 & 29.0 \\
\hline & No & 196 & 71.0 \\
\hline \multirow{2}{*}{ Smoke duration among current smoker $(\mathrm{n}=80)^{*}$} & $1-10$ years & 46 & 57.5 \\
\hline & More than 10 years & 34 & 42.5 \\
\hline \multirow{2}{*}{ Current alcohol consumption } & Yes & 117 & 42.4 \\
\hline & No & 159 & 57.6 \\
\hline \multirow{2}{*}{ Alcohol consumption in past } & Yes & 23 & 8.3 \\
\hline & No & 253 & 91.7 \\
\hline \multirow{2}{*}{ Physical activity level } & Low PAL & 88 & 31.9 \\
\hline & High/moderate PAL & 188 & 68.1 \\
\hline \multicolumn{4}{|l|}{ Biological factors of the respondents } \\
\hline \multirow[t]{2}{*}{ 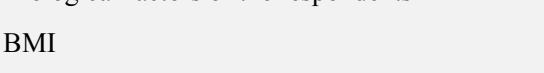 } & Non-obese & 257 & 93.1 \\
\hline & Obese & 19 & 6.9 \\
\hline \multirow{2}{*}{ CVD family history } & Yes & 82 & 29.7 \\
\hline & No & 194 & 70.3 \\
\hline
\end{tabular}

*Multiple response

The blood pressure measurement among respondents was found normal blood pressure $62.7 \%(\mathrm{n}=173)$, prehypertensive $14.5 \% \quad(\mathrm{n}=40)$, stage 1 hypertension $19.9 \%$ $(\mathrm{n}=45)$ and stage 2 hypertension $2.9 \%(\mathrm{n}=8)$.

Figure 2 shows the result of blood pressure measurement of the respondents.

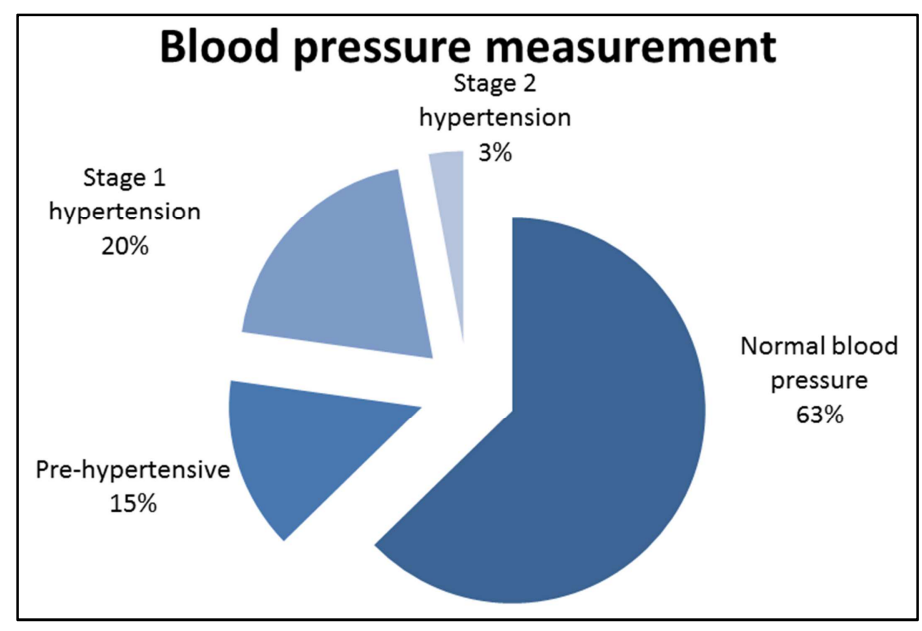

Figure 2. Measurement of blood pressure.

Bivariate analysis:

Factors associated with prevalence and risk factors of hypertension among adults.

Table 2 shows the socio-demographic characteristics 
associated with hypertension among the respondents.

Table 2. Socio-demographic characteristics associated with hypertension.

\begin{tabular}{|c|c|c|c|c|c|}
\hline \multirow{2}{*}{ Variables } & \multirow{2}{*}{ Category } & \multicolumn{2}{|l|}{ Hypertension } & \multirow{2}{*}{$95 \%$ CI } & \multirow{2}{*}{ p-value } \\
\hline & & Yes & No & & \\
\hline \multirow{2}{*}{ Age } & $18-40$ & $22(16.93 \%)$ & $108(83.07 \%)$ & \multirow[t]{2}{*}{$0.291-0.935$} & \multirow[t]{2}{*}{0.027} \\
\hline & $41-88$ & $41(28.09 \%)$ & 105(71.91\%) & & \\
\hline \multirow{2}{*}{ Sex } & Male & $42(28 \%)$ & $108(72 \%)$ & \multirow[t]{2}{*}{$0.285-0.927$} & \multirow[t]{2}{*}{0.025} \\
\hline & Female & $21(16.67 \%)$ & $105(83.33 \%)$ & & \\
\hline \multirow{2}{*}{ Ethnicity } & Bhramin/Chhetri & $29(21.48 \%)$ & $106(78.52 \%)$ & \multirow[t]{2}{*}{$0.490-1.513$} & \multirow[t]{2}{*}{0.603} \\
\hline & Others & $34(24.11 \%)$ & $107(75.89 \%)$ & & \\
\hline \multirow{2}{*}{ Religion } & Hindu & $43(19.02 \%)$ & 183(80.98\%) & \multirow[t]{2}{*}{$1.472-5.468$} & \multirow[t]{2}{*}{0.001} \\
\hline & Non-Hindu & $20(40 \%)$ & $30(60 \%)$ & & \\
\hline \multirow{2}{*}{ Marital status } & Unmarried & $6(13.64 \%)$ & $38(86.36 \%)$ & \multirow[t]{2}{*}{$0.195-1.206$} & \multirow[t]{2}{*}{0.113} \\
\hline & Evermarried & $57(24.67 \%)$ & $175(75.33 \%)$ & & \\
\hline \multirow{2}{*}{ Educational status } & Illiterate & $11(36.67 \%)$ & $19(63.33 \%)$ & \multirow[t]{2}{*}{$0.967-4.822$} & \multirow[t]{2}{*}{0.056} \\
\hline & Literate & $52(21.138 \%)$ & $194(78.862 \%)$ & & \\
\hline \multirow{2}{*}{$\begin{array}{l}\text { Socio-economic } \\
\text { status }\end{array}$} & Below poverty & $3(10.099 \%)$ & $30(90.901 \%)$ & \multirow[t]{2}{*}{$0.090-0.986$} & \multirow[t]{2}{*}{0.045} \\
\hline & Above poverty & $60(24.692 \%)$ & $183(75.308 \%)$ & & \\
\hline
\end{tabular}

Table 3 shows the behavioral characteristics associated with hypertension.

Table 3. Behavioral characteristics associated with hypertension.

\begin{tabular}{|c|c|c|c|c|c|}
\hline \multirow{2}{*}{ Variables } & \multirow{2}{*}{ Category } & \multicolumn{2}{|l|}{ Hypertension } & \multirow{2}{*}{$95 \%$ CI } & \multirow[b]{2}{*}{ p-value } \\
\hline & & Yes & No & & \\
\hline \multirow{2}{*}{ Current smoker } & Yes & $26(32.5 \%)$ & $54(67.5 \%)$ & \multirow[t]{2}{*}{$1.14-3.729$} & \multirow[t]{2}{*}{0.014} \\
\hline & No & $37(18.8775 \%)$ & $159(81.1225 \%)$ & & \\
\hline \multirow{2}{*}{$\begin{array}{l}\text { Smoking duration among } \\
\text { current smoker }\end{array}$} & $1-10$ years & $10(21.8 \%)$ & $36(78.2 \%)$ & \multirow[t]{2}{*}{$0.118-0.826$} & \multirow[t]{2}{*}{0.017} \\
\hline & More than 10 years & $16(47.05 \%)$ & $18(52.9 \%)$ & & \\
\hline \multirow{2}{*}{ Current alcohol consumer } & Yes & $36(30.74 \%)$ & $81(69.26 \%)$ & \multirow[t]{2}{*}{$1.228-3.844$} & \multirow[t]{2}{*}{0.007} \\
\hline & No & $27(16.98)$ & $132(83.02 \%)$ & & \\
\hline \multirow{2}{*}{$\begin{array}{l}\text { Consumption of sufficient fruits } \\
\text { and vegetables }\end{array}$} & Yes & $45(24.064 \%)$ & $142(75.936 \%)$ & \multirow[t]{2}{*}{$0.675-2.315$} & \multirow[t]{2}{*}{0.477} \\
\hline & No & $18(20.22 \%)$ & $71(79.78 \%)$ & & \\
\hline \multirow{2}{*}{ Physical activity level (PAL) } & Low PAL & $25(28.4 \%)$ & $63(71.6 \%)$ & \multirow[t]{2}{*}{$0.166-0.088$} & \multirow[t]{2}{*}{0.131} \\
\hline & High/moderate PAL & $38(20.2 \%)$ & $150(79.8 \%)$ & & \\
\hline
\end{tabular}

Table 4 shows the biological factors of the respondent associated with hypertension.

Table 4. Biological factors associated with hypertension.

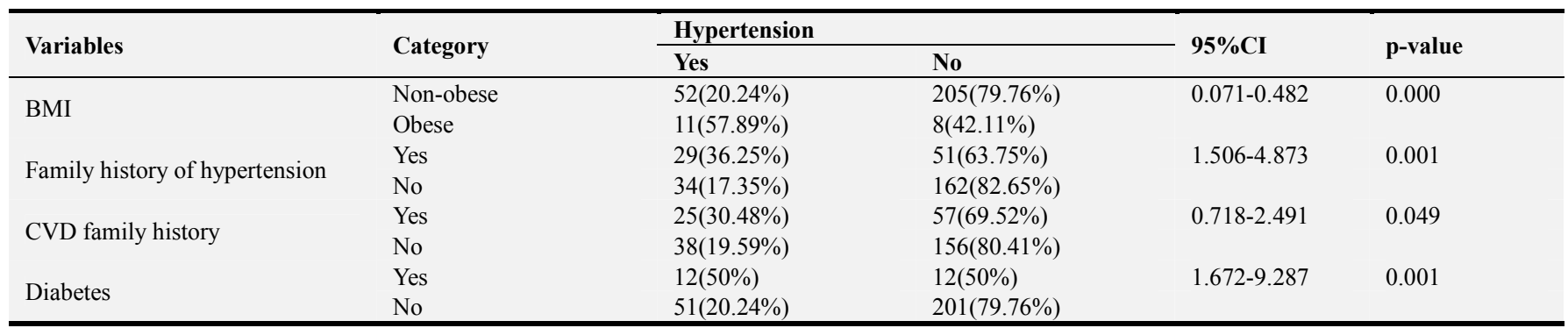

\section{Discussions}

The study found the prevalence of hypertension among adults was $22.8 \%$ which is similar to the study done in Central Nepal i.e. 22.4\% [12]. But it is less than the study in conducted in Kathmandu and Kritipur i.e. $32.5 \%$ and $37 \%$ respectively $[11,13]$. The present study found higher prevalence $(28.09 \%)$ among the age group $41-88$ whereas the age group of $18-40$ had $16.93 \%$ prevalence of hypertension which supported by the findings of the study in Kritipur municipality and among adults of Sipaghat VDC of Sindhupalchowk where hypertension was found higher with advancing of age $[11,14]$. It clearly supports the established fact that hypertension increases as age increases. Sex showed a positive association with hypertension while out of the total male $28.09 \%$ of them had hypertension whereas among female only $16.67 \%$ had hypertension which is similar to the findings of the study done in Sindhupalchowk, Dhapasi VDC of Kathmandu, and the Urban Varanasi of India [14, 16]. NDHS 2016 further, support these findings as it was found the prevalence of hypertension among female $17 \%$ and among male $23 \%$. It was found a higher prevalence in male also because of the risk factors that male are exposed to in higher amount such as smoking, alcohol consumption which is dominantly present among male over female in Nepalese 
society [17]. This study found the prevalence of hypertension among Brahmin/Chhetri (21.48\%) and among other ethnicities Janajati, Dalit, Others $(24.11 \%)$ and the prevalence of hypertension was similar to the findings of the study [11, 14]. Comparison of hypertension among evermarried and married it was seen higher among ever-married (24.67\%) than unmarried $(13.64 \%)$ and it is similar to the study of the findings $[11,16]$ it may be due to the responsibility towards the family, number of children, relationship conflicts that may lead to high prevalence among ever-married. Illiterate were found having the higher prevalence of hypertension (36.67\%) compared with literate (21.38\%) which is contrasted with the findings of Nepal Demographic Health Survey [17] but similar with the study conducted in central Nepal among adults [12]. These shows literate were aware of measurement of blood pressure. Socioeconomic status was found to be significantly associated with hypertension $(\mathrm{p}=0.045)$ whereas among the respondents above poverty level prevalence was found to be $24.692 \%$ which is similar with the study $[16,17]$ it may be a sedentary lifestyle among such people while this study is not similar to the findings of the study [11] where people below and above poverty level had a similar prevalence of hypertension.

In the assessment of behavioral factors, smoking of cigarettes was found significantly associated with hypertension $(p=0.014)$ where $32.5 \%$ of prevalence was found among current cigarette smoker. The significant association was found with the duration of smoking where (47.09\%) of hypertension prevalence was found among smoker who smoke for more than 10 years of smoking and the findings of this study are similar to the study done in Kritipur, central Nepal and Urban Varanasi of India [11, 12, 16]. The consumption of alcohol currently was found to be significantly associated with hypertension $(\mathrm{p}=0.007)$ which is similar to study in the municipality of Kathmandu, central Nepal, Urban Varanasi of India and rural Nepal [11, 12, 16, 18]. The consumption of sufficient fruits and vegetables and the prevalence of hypertension is not consistent with the findings of the other study as in this study [11, 19] who consume sufficient fruits and vegetables were found more having hypertension prevalence (24.064\%). In our study, it was found that physical the activity was not associated with the prevalence of hypertension while it is contrasted with the other study of findings $[11,18]$ were participation in good physical was found low hypertension among such people. These behavioral factors are a modifiable risk factor of hypertension. By reducing the consumption or quitting smoking, alcohol intake and consuming sufficient fruits and vegetables hypertension can be reduced, controlled or inhibit from causation.

BMI was found to be significantly associated with hypertension $(\mathrm{p}=0.000)$ were among obese $57.89 \%$ had hypertension which is supported with the findings of the other study [11, 13, 17]. Healthy lifestyle such as consumption of healthy food, daily exercise should be done because obesity is not related to only causation of hypertension but also other NCDs. The family history of hypertension was found significantly associated with the prevalence of hypertension were $36.35 \%$ of respondent had hypertension with a positive family history of hypertension and it is similar with the study conducted in global and regional level [14]. Also, the CVD family history and hypertension prevalence were found to be positively associated were $30.48 \%$ of the respondent had hypertension with a positive family history of CVD. The person with a positive family history of hypertension and CVD should be cautious as these genetic factors non-modifiable risk factors so blood pressure should be measured in a frequent interval. $50 \%$ of the hypertensive respondent had diabetes which is similar to the findings of other studies where diabetic were more hypertensive $[11,20]$.

\section{Conclusion and Recommendation}

\section{Conclusion}

The study revealed that the prevalence of hypertension and pre-hypertension among adults of Nagarjun municipality was $22.8 \%$ and $14.50 \%$. In this study, the prevalence of hypertension is found lower than the other study conducted in Kathmandu district.

The socio-demographic factors such as age, sex, religion, educational status, socio-economic status; behavioral risk factors such as cigarette smoking, duration of smoking, alcohol consumption, physical activity level; biological risk factors BMI, family history of hypertension and CVD and diabetes was significantly associated with hypertension. The significant association with many behavioral and biological risk factors suggests attention should be given to reduce them which are related to hypertension prevalence.

\section{Recommendation}

Attention should be given by the people as age increases, males, people with a positive family history of hypertension and CVD, diabetic people as these are nonmodifiable risk factors and people with such conditions are more likelihood of developing hypertension. Screening, early diagnosis and treatment would reduce the adverse impact on people.

Modifiable risk factors such as smoking and alcohol intake should be reduced or quit because limiting such factors also reduces their effects. Participation in exercise, participate in an activity that increases the physical level and healthy food intake should be taken to reduce obesity as it is also one of the modifiable risk factors of hypertension.

Health education program, screening camps and intervention program related to hypertension should be conducted in the municipality to minimize the risk factors of hypertension. The early detection and management would reduce the economic and health burden that people would face in the future.

\section{Relevance for the preparation of report}

The problems associated with non-communicable disease are significantly rising in Nepal as shown by several study. The raised blood pressure associates with the multiple causes for the development other disease. This is one of the main 
reason for the preparation of report in the context of Nepal. The present study can be used for planning and implementation of hypertension programs in the future by municipality. The behavioral factors like cigarette smoking, alcohol consumption, physical activity of person and biological factors higher BMI, family history of hypertension can plays significant role in developing hypertension are not known among people. The health education and promotion activities related to potential risk factor among people can alarm them to stay healthier.

\section{References}

[1] Report TS. Prevention, Detection, Evaluation and Treatment of High Blood Pressure. US Department of Health Human Services. NIH Public: 104.

[2] Global status report on noncommunicable diseases. Vol. Reprinted, World Health Organization. 2010. 176 p.

[3] K. Park. Park's Text Book of Preventive and Social Medicine. 23rd ed. Jabalpur, 482001 (M.P.): M/s Banarsidas Bhanot; $2015.925 \mathrm{p}$.

[4] Stamler R, Stamler J, Riedlinger WF, Algera G, Roberts RH. Family (parental) history and prevalence of hypertension. Results of a nationwide screening program. JAMA [Internet]. 1979 Jan 5 [cited 2019 Jun 29]; 241 (1): 43-6. Available from: http://www.ncbi.nlm.nih.gov/pubmed/758494

[5] WHO Technical Report Series. Forty-seve. Geneva, Switzerland: WHO Library Cataloguing in Publication Data; 1996. 108 p.

[6] Neupane D, McLachlan CS, Sharma R, Gyawali B, Khanal V, Mishra SR, et al. Prevalence of hypertension in member countries of South Asian Association for Regional Cooperation (SAARC): systematic review and meta-analysis. Medicine (Baltimore) [Internet]. 2014 Sep [cited 2019 Apr 23]; 93 (13): e74. Available from: http://www.ncbi.nlm.nih.gov/pubmed/25233326

[7] Vaidya A, Pathak RP, Pandey MR. Prevalence of hypertension in Nepalese community triples in 25 years: a repeat crosssectional study in rural Kathmandu. Indian Heart J [Internet]. 2012 [cited 2019 Jun 29]; 64 (2): 128-31. Available from: http://www.ncbi.nlm.nih.gov/pubmed/22572484

[8] Elliott WJ. The economic impact of hypertension. J Clin Hypertens (Greenwich) [Internet]. [cited 2019 Jun 29]; 5 (3 Suppl 2): 3-13. Available from: http://www.ncbi.nlm.nih.gov/pubmed/12826765

[9] Aryal KK, Mehata S, Neupane S, Vaidya A, Dhimal M, Dhakal $\mathrm{P}$, et al. The Burden and Determinants of Non
Communicable Diseases Risk Factors in Nepal: Findings from a Nationwide STEPS Survey. Kirchmair R, editor. PLoS One [Internet]. 2015 Aug 5; 10 (8): e0134834. Available from: http://dx.plos.org/10.1371/journal.pone.0134834

[10] Ritchie H, Roser M. Obesity \&amp; BMI. Our World Data [Internet]. 2017 Aug 11 [cited 2019 Jun 29]; Available from: https://ourworldindata.org/obesity

[11] Dhungana RR, Pandey AR, Bista B, Joshi S, Devkota S. Prevalence and Associated Factors of Hypertension: A Community-Based Cross-Sectional Study in Municipalities of Kathmandu, Nepal. International Journal of Hypertension. 2016 May; 2016: 1-10.

[12] Chataut J, Adhikari RK, Sinha NP. Prevalence and risk factors for hypertension in adults living in central development region of Nepal. Kathmandu University Medical Journal. 2011; 9 (33): 13-8.

[13] Maharjan B. Prevalence and Awareness of Hypertension among Adults and its Related Risk Factors. Journal of Nepal Health Research Council. December., 2017; 15 (3): 242-6.

[14] Manandhar N. Study on Associated Risk Factors of Hypertension at Sipaghat of Sindhupalchowk District, Nepal. Nepalese Journal of Statistics.2017; 1: 73-82.

[15] Dhakal S, Singh R, Naryan Yadav U, Gurung LB. Prevalence and Factors Associated with Hypertension among Elderly Population in Dhapasi VDC of Kathmandu District. J Hypertens Open Access [Internet]. 2017 Sep 12 [cited 2018 Nov 24]; 06 (03): 1-4. Available from: https://www.omicsonline.org/open-access/prevalence-andfactors-associated-with-hypertension-among-elderlypopulation-in-dhapasi-vdc-of-kathmandu-district-2167-10951000242-94156.html

[16] Singh S, Shankar R, Singh GP. Prevalence and Associated Risk Factors of Hypertension: A Cross-Sectional Study in Urban Varanasi. International Journal of Hypertension. 2017; 10.

[17] MOHP New ERA and ICF DHS Program. Nepal Demographic and Health Survey 2016. 2017; 222-38.

[18] Chataut J, Khanal K, Manandhar K. Prevalence and associated factors of hypertension among adults in rural Nepal: A community based study. Kathmandu University Medical Journal. 2015; 13 (52): 346-50.

[19] Ganesh Kumar S, Deivanai Sundaram N. Prevalence and risk factors of hypertension among bank employees in Urban Puducherry. International Journal of Occupational and Environmental Medicine .2014; 12 (48): 1-2.

[20] Ganesh KS, Naresh AGV, Bammigatti C, Ks G, Agv N, Bammigatti C. Prevalence and Risk Factors of Hypertension Among Male Police Personnel in Urban Puducherry, India. Kathmandu University Medical Journal. 2014; 48 (4): 242-6. 